MATUS, Jean Pierre. "Las formas de responsabilidad criminal por el hecho colectivo en el Derecho internacional y en el derecho interno chileno conforme a la Ley N ${ }^{\circ} 20.537$ '.

Polít. crim. Vol. 8, № 16 (Diciembre 2013), Art. 1, pp. 363-385. [http://www.politicacriminal.cl/Vol_08/n_16/Vol8N16A1.pdf]

\title{
Las formas de responsabilidad criminal por el hecho colectivo en el Derecho internacional y en el derecho interno chileno conforme a la Ley $\mathbf{N}^{\circ} 20.357^{*}$
}

\author{
Dr. Jean Pierre Matus A. \\ Profesor Titular de Derecho Penal de las universidades de Chile y Finis Terrae \\ jpmatus@derecho.uchile.cl
}
"Luego tomó la palabra Diomedes, valeroso en el grito de la guerra: $<<_{i}$ Néstor! Mi corazón y mi arrogante ánimo me invitan a penetrar en el campamento de los cercanos enemigos, los troyanos. Más si además me acompañara otro hombre, mayor será el consuelo y mayor será la audacia. Siendo dos los que van, si no es uno es otro quien ve antes cómo sacar ganancia; pero uno solo, aunque acabe viéndolo, es más romo para notarlo y tiene menos sutil el ingenio >>"1

\section{Resumen}

El artículo plantea la cuestión acerca de si la ley penal chilena es suficiente para abarcar todos los casos de responsabilidad penal individual por un hecho colectivo reconocidos por el Derecho penal internacional. Al respecto se concluye que la remisión de la Ley $\mathrm{N}^{\circ}$ 20.357 a las reglas generales del Código penal es insuficiente para lograr ese propósito. Al mismo tiempo, se propone una revisión de la actual tendencia a emplear conceptos tales como autoría mediata y de joint criminal enterprise, en vez de aplicar directamente las reglas del Derecho internacional que permiten la imputación a título de responsabilidad por el mando o del superior.

\section{Palabras clave}

Derecho penal internacional, Responsabilidad por el hecho colectivo, autoría mediata, empresa criminal conjunta, Ley chilena sobre crímenes internacionales.

\begin{abstract}
The article raises the question of whether Chilean criminal law is sufficient to cover all cases of individual criminal responsibility for a collective act recognized by International criminal law. In this regard we conclude that the remission of Law No. 20.357 to the

\footnotetext{
* Artículo producto del Proyecto FONDECYT No 1120097.

${ }^{1}$ HOMERO, Ilíada, Canto X, 220-226. Trad. E. Crespo, Madrid: Gredos, 2000, p. 193. El pasaje es citado por Aristóteles para demostrar el valor de la amistad en el incremento de las potencialidades humanas: "con amigos, los hombres están más capacitados para pensar y actuar" (ARISTÓTELES, Ética Nicomáquea, Libro VIII, 16-17. Trad. J. Pallí B., Madrid: Gredos, 2000, p. 216.
} 
MATUS, Jean Pierre. "Las formas de responsabilidad criminal por el hecho colectivo en el Derecho internacional y en el derecho interno chileno conforme a la Ley No 20.537 '.

general rules of the Penal Code is insufficient to achieve that purpose. At the same time, we propoe a review of the current tendency to use concepts such as indirect perpetration and joint criminal enterprise, instead of directly applying the rules of International law that allow the charge by way of command responsibility.

\section{Key words}

International criminal law, Responsibility for collective acts, indirect perpetration, joint criminal enterprise, Chilean law on international crimes.

\section{Introducción}

La Ley $\mathrm{N}^{\circ}$ 20.357, de 26 de junio de 2009, como parte de las negociaciones políticas para aprobar el Estatuto de Roma de la Corte Penal Internacional y con el propósito de establecer una regulación interna que, de conformidad con el principio de complementariedad del Art. 17 de dicho Estatuto, ${ }^{2}$ limitara la competencia de la Corte Penal Internacional para hechos que en el futuro ocurriesen en Chile, tipificó como delitos de derecho interno el genocidio, los crímenes de lesa humanidad y buena parte de los crímenes de guerra. Además, respecto de las reglas generales de responsabilidad individual, según la Moción origen del texto aprobado,

"se ha optado por mantener la relación de las normas que ella describe con las contenidas en la Parte General del Código Penal. De esta manera se establecen reglas especiales sólo en los casos que ha sido indispensable, por el singular objeto de regulación, cumpliendo en esta última parte además, con las obligaciones existentes en esta materia en el Estatuto de Roma". ${ }^{3}$

Estas modificaciones consistieron en hacer punibles la conspiración y la asociación ilícita para cometer delitos de lesa humanidad y genocidio (Arts. 14 y 15), incorporar una regulación sobre responsabilidad del superior (Art. 35) y otra sobre los efectos de las órdenes superiores (Arts. 36 y 38), así como una regla general acerca del contenido de la exigencia del conocimiento en el delito de genocidio (Art. 37). Además, se estableció la imprescriptibilidad de los delitos que tipifica (Art. 40), su "inderogabilidad tácita" (Art. 41), circunstancias agravantes especiales y la cooperación eficaz como atenuante (Art. 39).

De los numerosos problemas que esta nueva regulación pueden plantearnos, ${ }^{4}$ nos ocuparemos en este lugar sólo de uno de ellos: si es efectivo, como parece supuesto en la historia del texto legal aprobado, que las reglas generales de imputación de responsabilidad

\footnotetext{
${ }^{2}$ Sobre el sentido y alcance de este principio, véanse los trabajos recopilados por CÁRDENAS A., Claudia y FUENTES T., Ximena, Corte penal internacional y jurisdicciones estatales. El principio de complementariedad, Santiago: Thomson Reuters, 2012, especialmente pp. 3-21.

${ }^{3}$ BIBLIOTECA DEL CONGRESO NACIONAL, Historia de la Ley $N^{\circ} 20.357$, pp. 4 y ss.

${ }^{4}$ Una primera aproximación a las diferencias entre la configuración legal chilena y la del Estatuto de Roma, tanto desde el punto de vista de la tipificación de los delitos como de las reglas generales de responsabilidad penal, puede verse en CÁRDENAS, Claudia, "La implementación de los crímenes de competencia de la Corte Penal Internacional en la Ley $\mathrm{N}^{\circ}$ 20.357, Revista de Derecho (Valdivia), Vol. XXIII, N 2, pp. 23-44.
} 
penal por hechos colectivos de nuestro Código penal, con las modificaciones incorporadas por la Ley $\mathrm{N}^{\circ} 20.357$, permiten abarcar todos los casos de responsabilidad penal individual por un hecho colectivo reconocidos por el Derecho penal internacional, incluyendo las disposiciones que al respecto contempla el Estatuto de Roma.

Para estos efectos, entenderemos por un hecho colectivo aquél que supone o en los hechos se realiza con la intervención de alguna manera dos o más personas vinculadas entre sí. La responsabilidad individual por ese hecho colectivo significa que, en virtud de ese vínculo, cada uno de los intervinientes se considera responsable individualmente del hecho colectivo como un todo, aunque sólo hayan realizado o contribuido con o a una parte del mismo o de alguna manera intervenido en el colectivo al cual pertenecen quienes lo ejecutaron materialmente.

Históricamente, podemos encontrar un ejemplo de esta clase de responsabilidad individual en el relato de la suerte de los conjurados para matar a César, según la versión de Plutarco: todos y cada uno de ellos fueron considerados responsables del magnicidio, perseguidos y muertos por esa razón, a pesar de que no todos le apuñalaron ni todas las puñaladas de los que sí lo hirieron eran en sí mismas mortales. ${ }^{5}$

Además, como no es este el lugar para elaborar una tesis sobre todas las cuestiones que esta clase de imputación puede generar (¿es un hecho colectivo diferente al individual?, ¿responden todos los intervinientes en un hecho colectivo de la misma manera o habrá de establecerse diferenciaciones?, ¿estas diferenciaciones son ontológicas o normativas, derivadas únicamente de la forma cómo resuelve el asunto el legislador?, etc.), ${ }^{6}$ en lo que aquí se dirá se asume como válida la elaboración de los conceptos legales, según la doctrina y jurisprudencia local e internacional, pues de lo que se trata no es de una discusión sobre los fundamentos y validez de la responsabilidad individual por el hecho colectivo, sino de determinar el grado de complementariedad existente al respecto entre el Derecho penal chileno y los principios aceptados del Derecho penal internacional, de conformidad con su actual estadio de desarrollo.

\section{Los casos de responsabilidad por el hecho colectivo en el Derecho chileno. Breve introducción.}

Nuestra doctrina y jurisprudencia reconocen en el Derecho penal chileno las siguientes formas o modos de responsabilidad individual por el hecho colectivo: la conspiración (Art. $8^{\circ}$ del Código Penal, en adelante "CP”), la asociación ilícita (Art. $292 \mathrm{CP}$ ), la coautoría

\footnotetext{
${ }^{5}$ PLUTARCO, Vidas Paralelas. Vida de César, LXV-LXIX. Trad.A. Ranz R., Madrid: Ed. Iberia, 1959, pp. 400-403.

${ }^{6}$ Para dimensionar la extensión de una investigación en la materia tómese en cuenta que la última edición del texto de Roxin que mayor influencia ha tenido entre nosotros y en todos los países donde predomina en el estudio del Derecho penal la perspectiva de las dogmática alemana tiene 820 páginas, sin contar las 21 iniciales (ROXIN, Claus, Täterschaft und Tatherrschaft, 8a Ed., Berlín: De Gruyter, 2006). En castellano, menos influyente pero no menos extensa es la obra de García-Díaz y Conlledo, que tiene 787 páginas (GARCÍA-DÍAZ Y CONLLEDO, Miguel, La autoría en Derecho penal, Barcelona: PPU, 1991).
} 


\section{MATUS, Jean Pierre. "Las formas de responsabilidad criminal por el hecho colectivo en el Derecho internacional y en el derecho interno chileno conforme a la Ley $\mathrm{N}^{\circ} 20.537$ '.}

(Art. $15 \mathrm{~N}^{\circ} 1$ y $3^{\circ} \mathrm{CP}$ ), la autoría mediata en aparatos organizados de poder. ${ }^{7}$ Por su parte, la Ley $\mathrm{N}^{\circ} 20.357$ no pretende modificar o adecuar estas reglas a los casos reconocidos en el Derecho penal internacional en general y en el Estatuto de Roma por el que se estableció la Corte Penal Internacional (en adelante, "ER"), sino que, sencillamente, respecto de los delitos de lesa humanidad y genocidio establece en sus Arts. 14 y 15 el castigo de la conspiración para su ejecución y de la asociación ilícita para cometerlos. ${ }^{8}$

Respecto del nexo o vínculo entre los intervinientes en el hecho colectivo, tratándose de los casos de conspiración y asociación ilícita éste lo constituye la existencia de un acuerdo de

${ }^{7}$ POLITOFF, Sergio; MATUS, Jean Pierre; RAMÍREZ, Ma. Cecilia, Lecciones de Derecho penal chileno. Parte general, $2^{\mathrm{a}}$ Ed., Santiago: Ed. Jurídica de Chile, 2004, pp. 395-444, especialmente, pp. $391-393$ (conspiración y asociación ilícita), 415-419 (coautoría), y pp. 410 (autoría mediata en aparatos organizados de poder). Allí se ofrece una exposición que sigue la teoría diferenciadora de la participación criminal con base en la teoría del dominio del hecho de Roxin, que distingue entre la figura principal del hecho, quien o quienes tienen o comparten el dominio fáctico sobre el mismo, en el sentido de la capacidad de decidir su ejecución o terminación, respecto de los demás intervinientes, calificados como partícipes en un hecho ajeno. La regla subyacente a la responsabilidad personal por el hecho colectivo sería el principio de imputación recíproca, según el cual a los coautores (esto es, a quienes comparten el dominio del hecho) se les puede imputar recíprocamente lo que hacen $u$ omiten los otros coautores, para hacerlos responsables del hecho (colectivo) total. De conformidad con este punto de vista, la inducción y la complicidad, cuya penalidad se hace depender de que un autor ejecute el delito, sólo pueden verse como formas de participación en el delito de un autor (la figura principal que tiene el dominio del hecho). El encubrimiento, por su parte, se considera una especie de delito sui generis, asimilado a la participación criminal sólo por la expresa disposición legal del Art. 14 del Código penal.

No obstante lo anterior, existen entre nosotros propuestas minoritarias y todavía no desarrolladas completamente que ofrecen una interpretación diferente de las disposiciones legales que regulan las formas de la responsabilidad criminal en Chile, bajo el punto de vista de un concepto unitario, que pone énfasis en el aspecto común a todas ellas ("contribución a la ejecución de un delito") y destaca que las diferenciaciones penológicas actuales entre ellas no pueden considerarse sino una regla general, sujeta a excepciones y a la discreción política, esto es, un resultado normativo y no ontológico (MATUS A., Jean Pierre, Evolución histórica de la doctrina penal chilena, desde 1874 hasta nuestros días, Santiago: Thomson Reuters, 2011, pp. 225-250. Antes, en el mismo sentido: MATUS A., Jean Pierre: "Sergio Yáñez: obra e influencia. La dogmática chilena actual”, Revista de Derecho (Coquimbo), Vol. 14 (2007), N 1, pp.113-130.

${ }^{8}$ No se considera aquí el reconocimiento de una forma de responsabilidad por el mando que establece el Art. 35 de la Ley $\mathrm{N}^{\circ}$ 20.357, pues en este caso se trata más bien de un supuesto de responsabilidad por el hecho ajeno, más o menos delimitado, que no implica necesariamente la intervención del superior en el hecho que se le atribuye y que, por lo mismo, el Estatuto de Roma le ha reservado una regulación especial en su Art. 28, bajo el epígrafe responsabilidad de los jefes y otros superiores, separada de las formas de responsabilidad individual previstas en su Art. 25. Con todo, que es posible una suerte de solapamiento entre esta especial forma de responsabilidad por el hecho ajeno y los resultados de las elaboraciones teóricas sobre todo en relación con la llamada autoría mediata y las jurisprudenciales de la denominada joint criminal entreprise es un hecho que no se debe desconocer y sobre el cual volveremos más adelante. Para apreciar estas posibilidades de solapamiento, véase, respecto del Derecho chileno, la obra de WINTER E., Jaime, La responsabilidad por el mando en el Derecho penal internacional, Tesis Uch, Santiago: 2009, especialmente las pp. 137-152. Winter concluye que esta forma de responsabilidad se trataría, en nuestras categorías usuales de autoría y participación, de una forma de complicidad o participación accesoria en el hecho de los subordinados y no de una forma de responsabilidad autónoma del superior (p. 152). Los antecedentes y desarrollo de esta doctrina, en el famoso caso Yamashita, pueden verse en LAEL, Richard L., The Yamashita Precedent. War Crimes and Command Responsability, Delaware: Wilmington, 1982. Sobre el estado actual de la doctrina y su aplicación en los Tribunales ad hoc, véase METTRAUX, Guénaël, The Law of Command Responsability, Oxford / New York: Oxford University Press, 2009. 


\section{Polít. crim. Vol. 8, № 16 (Diciembre 2013), Art. 1, pp. 363-385. [http://www.politicacriminal.cl/Vol_08/n_16/Vol8N16A1.pdf]}

voluntades o concierto, sea para la ejecución de un delito determinado (conspiración), ${ }^{9}$ o para organizar una asociación con el objeto de atentar contra el orden social, contra las buenas costumbres, contra las personas o las propiedades (asociación ilícita). ${ }^{10}$ También el concierto para la distribución de las funciones en la ejecución es el nexo subjetivo exigido para la coautoría, a lo que la doctrina dominante, de conformidad con la teoría del dominio del hecho, agrega la existencia objetiva de tal dominio, funcionalmente compartido entre los coautores. ${ }^{11}$ En los casos de autoría mediata en aparatos organizados de poder, el nexo entre quienes se encuentran en la cúspide de la organización y los ejecutores materiales está formado por la existencia objetiva de dicho aparato organizado, requiriéndose para la imputación del hecho colectivo a unos y otros, además, que los primeros (autores mediatos) tengan dominio sobre el aparato y los segundos (autores inmediatos), dominio sobre la ejecución del hecho concreto que se imputa a todos como autores del hecho colectivo. ${ }^{12}$

Como las reglas generales de determinación de penas de los Arts. 50 y siguientes del Código penal no distinguen entre quienes son autores de un hecho colectivo y quienes lo son de un hecho individual, imponiéndoles a todos por igual la pena asignada por la ley para el delito consumado y las rebajas que allí se establecen para los casos de tentativa y frustración, habrá que concluir que, general y normativamente, la ley chilena no distingue a efectos de estimar la gravedad de un hecho entre uno de carácter individual y otro de carácter colectivo, salvo excepcionalmente, cuando se permite el castigo de la asociación ilícita con independencia de los delitos que se comenten con motivo u ocasión de su organización (Art. 494bis CP), y en ciertos casos en que la actuación grupal se pueda estimar como una agravante, sea la genérica del Art. $12 \mathrm{~N}^{\circ} 11$ (ejecutar el delito "con

\footnotetext{
${ }^{9}$ POLITOFF / MATUS / RAMÍREZ, Lecciones $P G$, cit. nota n ${ }^{\circ}$ 7, p. 392. En el mismo sentido, MERA F., Jorge, "La conspiración", en: COUSO S., Jaime y HERNÁNDEZ B., Héctor, Código penal comentado, Santiago: Thomsom Reuters, 2011, pp.173-176.

${ }^{10}$ Según Grisolía: organizarse "en torno de un objetivo común que comprende la finalidad de cometer delitos" (GRISOLÍA C., Francisco, "El delito de asociación ilícita", Revista Chilena de Derecho, Vol. 31 (2004), N¹, pp. 75-88, p. 76). El hecho de que el vínculo u organización que presupone una asociación ilícita resulta exclusivamente o en primer lugar del acuerdo de voluntades de sus miembros es precisado por Guzmán D., al sostener que se trata de un delito de expresión, en el sentido propuesto por Kern, el cual se comete "mediante una declaración provista de contenido": "el acuerdo de asociarse", cuyo resultado no es otro que el "quedar asociados" (GUZMÁN D., José Luis, Estudios y Defensas Penales, Santiago: Legal Publishing, 2005, pp. 43 y ss.). Dada esta característica, lleva razón Etcheberry cuando sostiene que "a veces es difícil distinguir lo que es una asociación ilícita de un simple concierto o conspiración para delinquir" (ETCHEBERRY, Alfredo,

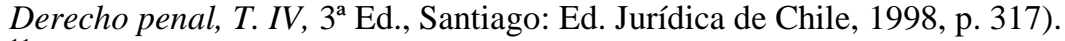

${ }^{11}$ CURY U., Enrique; MATUS A., Jean Pierre, "Comentario al Art. $15 \mathrm{~N}^{\circ} 1$ ", en: POLITOFF L., Sergio; ORTIZ Q., Luis (Dirs.); MATUS A., Jean Pierre, Texto y comentario del Código penal chileno, T. I, Santiago: Ed. Jurídica de Chile, 2002, pp. 237-239.

${ }^{12}$ POLITOFF L., Sergio, "El 'Autor detrás del autor'. De la autoría funcional a la responsabilidad penal de las personas jurídicas", en: POLITOFF L., Sergio; MATUS A., Jean Pierre, Gran criminalidad organizada y tráfico ilícito de estupefacientes, Santiago: Ed. Conosur, 2000, pp. 333-414, pp.393-396. Significativamente en contra de admitir la autoría mediata en aparatos organizados de poder como una forma de responsabilidad individual por el hecho colectivo, entre nosotros se pronuncia Cury, quien siguiendo las tesis de E. Gimbernat y G. Jakobs, estima que la teoría se habría desarrollado en Alemania por una suerte de "sentimiento de culpabilidad nacional" por el genocidio y las atrocidades de la dictadura nacionalsocialista y que los supuestos que se señalan corresponderían o bien a casos de de participación en un hecho ajeno por medio de inducción o de coautoría, respectivamente (CURY U., Enrique, Derecho penal. Parte general, $7^{\mathrm{a}}$ Ed., Santiago: Ed. U. Católica de Chile, 2005, pp. 606 y ss.)
} 
MATUS, Jean Pierre. "Las formas de responsabilidad criminal por el hecho colectivo en el Derecho internacional y en el derecho interno chileno conforme a la Ley $\mathrm{N}^{\circ} 20.537$ '.

auxilio de gente armada o de personas que aseguren o proporcionen la impunidad") ${ }^{13}$ o una especial, p. ej., la del $\mathrm{N}^{\circ} 3$ del Art. 456 bis, cuando se agravan las penas de los delitos de hurto y robo si son "dos o más los malhechores", ${ }^{14}$ o la de la letra a) del Art. 19 de la Ley $\mathrm{N}^{\circ} 20.000$, que agrava las penas en los delitos de tráfico ilícito de estupefacientes "si el imputado formó parte de una agrupación o reunión de delincuentes". ${ }^{15}$

De este modo, nuestra legislación se aparta, como regla general, de lo que enseña Homero desde tiempos inmemoriales: que la actividad colectiva no es equivalente a la de uno solo ni tampoco a la de varios actuando aisladamente. ${ }^{16}$ En cambio, las reglas generales de coautoría y conspiración pueden formularse como meras ampliaciones típicas de la punibilidad del hecho individual, ${ }^{17}$ aunque el objeto regulado sea un hecho colectivo y no uno individual. Sólo en el tratamiento excepcional de la asociación ilícita su penalidad independiente parece reflejar la diferencia entre un hecho individual al que otros contribuyen y el hecho colectivo por el que se responde individualmente, ${ }^{18}$ diferencia que también es posible apreciar en la posibilidad de agravación de las penas que por la actuación grupal se prevé en ciertos casos.

\section{Responsabilidad por el hecho colectivo en el Derecho penal internacional. Breve introducción: conspiracy, membership, joint criminal enterprise, co-perpetration, indirect perpetration.}

Mientras en el derecho local, la responsabilidad individual por el hecho colectivo parece excepcional, al menos desde el punto de vista normativo (considérese únicamente el fraseo del Código penal chileno, resaltando el castigo "al que" ejecute u omita la conducta descrita y el ámbito más bien limitado de aplicación de las figuras de conspiración y asociación ilícita); en el Derecho penal internacional lo normal, al menos desde el punto de vista

\footnotetext{
${ }^{13}$ Las limitaciones y alcance de esta figura pueden verse en KÜNSEMÜLLER L., Carlos, "Comentario al Art. 12, 11 a.", en: POLITOFF/ ORTIZ / MATUS, Texto y Comentario, cit. nota no 11, pp. 204 y ss.

${ }^{14}$ Circunstancia que, como señala Labatut, reemplazó a la antigua "cuadrilla", para cuya concurrencia se exigían cuatro o más individuos. Como se sabe, el punto de discusión no es actualmente si se trata o no de una pluralidad de sujetos, sino si éstos han de ser o no delincuentes convictos para entenderlos como "malhechores" (LABATUT G., Gustavo, Derecho penal, T. II., $7^{\text {a }}$ Ed. actualizada por J. Zenteno, Santiago: Ed. Jurídica de Chile, 1983, p. 217).

${ }^{15}$ Sobre el alcance e interpretación de esta figura, véase POLITOFF L., Sergio; MATUS A., Jean Pierre; RAMÍreZ G., Ma. Cecilia, Lecciones de Derecho penal chileno. Parte Especial, 2a Ed., Santiago: Ed. Jurídica de Chile, 2005, pp. 614 y ss.

${ }^{16}$ Como, en general, desde el punto de vista de la criminología positivista de principios del siglo XX, afirmaba Del Río al sostener que "circunstancias hay también en que la codelincuencia por sí sola es una manifestación clara de mayor temibilidad de las personas que se unen para delinquir" (DEL RÍO C., Raimundo, Derecho penal, T. II, Santiago: Ed. Nascimento, 1935, p. 263).

${ }^{17}$ Así expresamente se pronuncia NOVOA M., Eduardo, Curso de Derecho penal. Parte general, t. II, $3^{\mathrm{a}}$ Ed., Santiago: Ed. Jurídica de Chile, 2005, p. 178, quien en todo caso reconoce que, desde el punto de vista criminológico, "cuando la delincuencia se organiza en grupos permanentes puede adquirir una fuerza y disciplina que la hacen más temible para la sociedad" (p. 174).

${ }^{18}$ De nuevo, es Del Río quien con claridad señala esta diferencia: "El fundamento jurídico de la sanción de las asociaciones ilícitas es preventivo, y está en el riesgo social que crea una organización destinada a delinquir, y en la peligrosidad que revelan sus jefes, comandantes, provocadores, participantes y ayudantes" (DEL RÍO C., Raimundo, Derecho penal, T. III, Santiago: Ed. Nascimento, 1935, p. 247)
} 
fáctico, es la actuación colectiva, considerada una las características inherentes de muchos crímenes perpetrados en tiempos de guerra. Según el Tribunal Penal Internacional para la Ex Yugoslavia (en adelante, "ICTY"), en tales circunstancias,

“muchas personas teniendo un propósito común se embarcan en una actividad criminal que luego es ejecutada conjuntamente o por algunos de los miembros de esa pluralidad de personas". 19

Los nombres de las formas de responsabilidad individual por tales hechos colectivos desarrolladas por el Derecho penal internacional, desde la instalación del Tribunal Penal Militar de Núremberg, han sido las siguientes: conspiración (conspiracy), pertenencia a una organización criminal (membership in a criminal organization), empresa criminal conjunta (joint criminal enterprise), coautoría (co-perpetration) y autoría mediata (indirect perpetration).

Las dos primeras (conspiracy y membership in a criminal organization), a pesar de que pueden entenderse reconocidas como parte de los principios del Derecho internacional mediante la Resolución 95(I) de la Asamblea General de las Naciones Unidas, de diciembre de 1946, que confirmó los principios contenidos en el Estatuto del Tribunal Penal Internacional de Núremberg y de su jurisprudencia, ${ }^{20}$ no fueron incorporadas como regla general en los Estatutos de los Tribunales ad hoc creados en la década de 1990 ni se encuentran mencionadas explícitamente en las reglas del Art. 23 del Estatuto de Roma.

Posteriormente a Núremberg, sólo en el Art. III b) de la Convención para la prevención y sanción del delito de genocidio aparece claramente establecido un caso de conspiracy. ${ }^{21}$ Por esta vía se incorporó a los Estatutos de los Tribunales Ad hoc para la ex Yugoslavia y Ruanda, y sigue siendo aplicada a casos actuales, como el caso Musema. ${ }^{22}$ Y también se reconoce que el texto del Art. 25.3.d) del Estatuto de Roma es producto de una negociación política entre quienes se oponían tajantemente a su incorporación y quienes la proponían y que, por ello, puede decirse que en dicho Estatuto "es reconocida una suerte de conspiracy". ${ }^{23}$ Por ello afirma Bassiouni, con razón, que a pesar de todo, la conspiracy "ha encontrado su camino" en el actual Derecho penal internacional. ${ }^{24}$

Menos suerte ha corrido la pertenencia a una organización criminal, pues ningún Estatuto posterior a Núremberg la ha reconocido como una forma de responsabilidad individual en un hecho colectivo. Es más, desde un principio ella fue limitada, pues a pesar de que el Estatuto del Tribunal Militar Internacional establecía literalmente la responsabilidad penal

\footnotetext{
${ }^{19}$ ICTY, Prosecutor v. Tadic, Caso No IT-94-1-A, 15.07.1999, párr. 194.

${ }^{20}$ Véase la Resolución en http://www.un.org/spanish/documents/ga/res/1/ares1.htm. Una nota explicativa del destino e influencia posterior de la misma ha sido preparada por Antonio CASSESE, y se encuentra disponible en http://untreaty.un.org/cod/avl/pdf/ha/ga_95-I/ga_95-I_s.pdf

${ }^{21}$ El texto oficial en inglés dice: "Conspiracy to commit genocide". En español, en cambio, dice "La asociación para cometer genocidio".

${ }^{22}$ Tribunal Penal Internacional para Ruanda (ICTR), Prosecutor v. Musema, Caso N ICTR-96-13-A.

${ }^{23}$ BENTEKAS, Ilias, International Criminal Law, 4ª Ed., Oxford: Hart Publishers, 2010, p. 66.

24 BASSIOUNI, M. Cherif, Introduction to International Criminal Law, Nueva York: Transnational Publishers, 2003, p.8, nota 27.
} 
MATUS, Jean Pierre. "Las formas de responsabilidad criminal por el hecho colectivo en el Derecho internacional y en el derecho interno chileno conforme a la Ley N²0.537'.

individual por la mera pertenencia a una organización declarada criminal, ${ }^{25}$ la jurisprudencia de Núremberg matizó esta proposición, asimilando el castigo por la pertenencia a la conspiracy, según la doctrina anglosajona del propósito o designio común ("there must be a group bound together and organized for a common purpose"), excluyendo el castigo de personas que se incorporaban a la organización sin conocimiento de su propósito criminal o eran adscritas a ella por el Estado, sin implicarse personalmente en la comisión de actos criminales. Por lo tanto, la mera pertenencia a una organización no se considera criminal, requiriéndose una incorporación voluntaria con conocimiento del propósito criminal o la comisión efectiva de un acto criminal por parte del acusado, como miembro de esa organización. ${ }^{26}$

En cambio, sobre la base de los casos fallados en los tribunales posteriores a la II Guerra Mundial, el Tribunal Penal Internacional para la Ex Yugoslavia (en adelante "ICTY") ha desarrollado una forma de responsabilidad individual por hechos colectivos que no estando expresamente contemplada en su Estatuto, recoge el aspecto esencial de la conspiracy y la pertenencia a una organización criminal, que estima constituye una regla consuetudinaria del Derecho internacional que ha de entenderse como una forma de "comisión" de los crímenes bajo su jurisdicción: la actuación de varios siguiendo un "propósito o designio común". ${ }^{27}$ A esta forma de responsabilidad individual por un hecho colectivo llevado adelante bajo un propósito o designio común la ha denominado joint criminal enterprise (empresa criminal conjunta, en adelante "JCE").

Según el fallo en el caso Tadic, la doctrina del "propósito" o "designio común" comprendería tres categorías de "criminalidad colectiva": en la primera (JCE I), todos los participantes del hecho actúan siguiendo un propósito común y poseen la misma intención de cometer un crimen, y uno o más de ellos efectivamente lo perpetran. En la segunda (JCE II), que se entiende como una "variante" de la primera, se interviene, compartiendo el designio común, en un sistema ya existente de maltrato y tortura de personas detenidas (los casos de los Campos de Concentración, donde se encontraron igualmente responsables a guardias y superiores). Y en la tercera (JCE III), se trataría de situaciones en las cuales durante la realización material de un designio común, "uno de los perpetradores comete un acto que va más allá del designio común, pero que, sin embargo, era una consecuencia natural y previsible de llevar a efecto ese propósito común". Al respecto, la Cámara de

\footnotetext{
25 "Art. 10. In cases where a group or organization is declared criminal by the Tribunal, the competent national authority of any Signatory shall have the right to bring individual to trial for membership therein before national, military or occupation courts. In any such case the criminal nature of the group or organization is considered proved and shall not be questioned.".

${ }^{26}$ BASSIOUNI, Introduction, cit. nota $\mathrm{n}^{\circ} 24, \mathrm{p} .85$.

${ }^{27}$ ICTY, Prosecutor v. Tadic, Caso N IT-94-1-A, 15.07.1999, párrafos 190, 194 y 195. La primera vez que se empleó el término joint criminal enterprise para identificar este modo de responsabilidad individual por la comisión de un crimen internacional, diferenciado de la complicidad o encubrimiento, fue en el fallo de la Cámara de Juicio del ICTY en Prosecutor v. Furundzija, Caso N IT-95-17/1-T, 10.12.1998, pár. 216. Antes, en Prosecutor v. Delalic, Mucic, Delic and Landzo, Caso N IT-96-21-T, 16.11.1998, pár. 328, se había hecho la primera mención a la doctrina del "designio común" para considerar responsables de la comisión de un crimen cometido por "miembros de un grupo actuando con un propósito criminal común" a "todo el que a sabiendas participase de ese propósito y directa y sustancialmente contribuyese a su realización”.
} 


\section{Polít. crim. Vol. 8, № 16 (Diciembre 2013), Art. 1, pp. 363-385. \\ [http://www.politicacriminal.cl/Vol_08/n_16/Vol8N16A1.pdf]}

Apelaciones del ICTY ofrece el siguiente ejemplo: si un grupo de personas decide la expulsión forzada de un grupo étnico desde un pueblo o ciudad, y se dispara y mata a una o más de las víctimas en el curso de su expulsión, todos los participantes en el plan son igualmente responsables por el asesinato porque era "previsible que en una expulsión forzada de civiles a punta de pistola pudiese resultar la muerte de uno o más de esos civiles". ${ }^{28}$

Según Boas, Bischoff y Reid, la "poco convencional metodología" empleada por el ICTY en Tadic para establecer la existencia y requisitos de estas tres formas de participación en una joint criminal enterprise ha dejado expuesta su doctrina a una "crítica justificada". Entre tales críticas se destacan, en lo metodológico, no sólo que el fallo cita muchos casos que no son públicos o cuyas decisiones no aparecen fundamentadas, extrayendo de ellas conclusiones no necesarias, sino principalmente que la jurisprudencia citada no puede considerarse en general como fuente de una costumbre internacional, esto es, de una práctica estatal extendida y consistente con la convicción de que con ella se está cumpliendo una regla jurídica; ${ }^{29}$ y en lo conceptual, que el fallo parece confundir la coperpetración, esto es, la realización conjunta de un crimen entre varios que se dividen o no los roles en su ejecución, con la intervención individual en un hecho colectivo cuyo propósito o designio común se comparte, pero cuya realización material es ejecutada por otras personas que comparten dicho designio. ${ }^{30}$

Por otra parte, el Art. 25 del Estatuto de Roma tampoco recoge en su literalidad el concepto de joint criminal enterprise. Ello ha dado lugar a que sea discutida su adopción en este ámbito por los juristas con formación continental (y más precisamente, por aquellos influidos por la doctrina alemana del Derecho penal y entre los internacionalistas, por los trabajos de Kai Ambos), y exista una fuerte tendencia a reemplazar esta construcción por las formas tradicionales de imputación del derecho interno alemán, basadas en la teoría del dominio del hecho, incluyendo la aplicación de los conceptos de coautoría (coperpetration) y la teoría de la autoría mediata (indirect perpetration), en los términos

\footnotetext{
${ }^{28}$ ICTY, Prosecutor v. Tadic, cit. nota n 27, párrs. 195, 197, 202-204 y 220.

${ }^{29}$ BOAS, Gideon; BISCHOFF, James; REID, Natalie, International criminal law practitioner library, Vol. I, Cambridge: Elsevier Science Publishers B.V, 2011, pp. 17 y ss.

${ }^{30}$ En efecto, en todos los casos relativos a la II Guerra Mundial que se citan en Tadic de JCE I lo que existe es la realización de elementos de los delitos que se tratan por los responsables, de forma total o parcial, o en los cuales al menos éstos están presentes. Pero ese no es el caso relevante de participación en un hecho colectivo. Por ejemplo, en el caso Sandrock y otros, uno de los acusados ordenó la muerte de un prisionero de guerra, otro le disparó y un tercero montó guardia. El Tribunal británico que los condenó estimó que habían actuado bajo un "propósito común". Para la ICTY, lo relevante es que aquí "It was clear that they all had had the intention of killing the British soldier, although each of them played a different role" (ICTY, Prosecutor v. Tadic, cit. $\mathrm{n}^{\circ}$ 27, párr. 197). Sin embargo, la impropiedad de emplear el término "co-perpetración" para referirse a la participación en una JCE ha sido puesta de manifiesto incluso por esta jurisprudencia posterior, como aparece en ICTY, Prosecutor v. Milutinovic, Sainovic and Ojdanic, Caso N ${ }^{\circ}$ IT-99-37-AR72, Cámara de Apelaciones, donde se señala: "The Prosecutor pointed out in its indictment against Ojdanic that its use of the Word 'committed' was not intended to suggest that any of the accused physically perpetrated any of the crimes charged, personally. 'Committing', the prosecution wrote, 'refers to participation in a joint criminal enterprise as a co-perpetrator. Leaving aside the appropriateness of the use of the expression 'coperpetration' in such context, it would seem therefore that the Prosecution charges co-perpetration in a joint criminal enterprise as a form of "commission".
} 
MATUS, Jean Pierre. "Las formas de responsabilidad criminal por el hecho colectivo en el Derecho internacional y en el derecho interno chileno conforme a la Ley $\mathrm{N}^{\circ} 20.537$ '.

desarrollados por Roxin, ${ }^{31}$ tendencia que parece haberse asentado en los escasos fallos de la Corte Penal Internacional. ${ }^{32}$

En consecuencia, según Kai Ambos, sólo el caso de la JCE I podría sostenerse recogido dentro del Art. 25.3.a) del Estatuto de Roma (cometer el crimen "con otro", o más significativamente, como aparece en el texto en inglés, "jointly with another"), al no ser más que una forma de co-perpetración o coautoría subsumible en la teoría del "dominio del hecho"; ${ }^{33}$ mientras que las modalidades de JCE II no reconducibles a la co-perpetration y JCE III, vinculadas más bien a la conspiracy anglosajona y a la teoría de la responsabilidad por la membresía en una organización criminal, como se contemplaban en el Estatuto de Núremberg, no estarían recogidas en el Estatuto de Roma. Es más, ellas ni siquiera podrían subsumirse en el caso de responsabilidad por el hecho colectivo del Art. 23.d), que exigiría una contribución intencional a una actividad que entrañe la comisión de un crimen de competencia de la Corte o a sabiendas de que el grupo tiene la intención de cometer dicho crimen. ${ }^{34}$

En cambio, tal como ya se dijo, según Kai Ambos y la propia Corte Penal Internacional ha declarado en el caso Lubanga, lo que sí permitiría el texto del Art. 25.3 a) del Estatuto, al emplear la expresión cometer el crimen "por conducto de otro" ( "through another") sería considerar el resto de los casos que los tribunales Ad hoc entienden como JCE, como supuestos de autoría mediata en aparatos organizados de poder, en el evento que concurran los requisitos de la misma.

Sin embargo, una cosa es el alcance de la responsabilidad penal derivada de las disposiciones del Estatuto de Roma y su interpretación, y otra bien distinta el efecto que ello pueda tener en el Derecho penal internacional, dado el limitado alcance de dicho Estatuto (no ratificado por los países más populosos del mundo, como China, Estados Unidos, Rusia e India); el hecho de que todavía operan tribunales Ad hoc e híbridos siguiendo, por ejemplo, la teoría de la joint criminal enterprise; la existencia de un Consejo de Seguridad que conserva las facultades para establecer otros tribunales de esta especie de conformidad con el Capítulo VII de la Carta de las Naciones Unidas; y el carácter

\footnotetext{
${ }^{31}$ Así, por ejemplo, BANTEKAS, International criminal law, cit. nota $\mathrm{n}^{\circ} 23$, p. 59, quien denomina esta forma de responsabilidad como "indirect perpetration", afirmando que se encuentra reconocida en el Art. 25.3.a) del Estatuto de Roma en la expresión cometer el crimen "por conducto de otro, sea éste o no penalmente responsable" y que, "de hecho, ella nunca ha sido utilizada por los tribunales ad hoc".

${ }^{32}$ Véase el fallo de la Cámara de Juicio I de la Corte Penal Internacional en Prosecutor v. Thomas Lubanga Dyilo, ICC O1/04-01/06, 14.03.2012. Aprobando la adopción de la teoría del dominio del hecho, véase al respecto AMBOS, Kai, "El primer fallo de la Corte Penal Internacional (Prosecutor v. Lubanga): un análisis integral de las cuestiones jurídicas", InDret 3/2012, pp. 25-37. Esta evolución hacia la adopción de las categorías dogmáticas alemanas con abandono de la jurisprudencia de los tribunales ad-hoc por parte de la Corte Penal Internacional, donde la mayoría de los jueces han sido formados en el sistema de origen alemán, había sido predicha ya en 2008, en MATUS A., Jean Pierre, La transformación de la teoría del delito en el Derecho penal internacional, Barcelona: Atelier, 2008, pp. 139 y ss.

${ }_{33}$ AMBOS, Kai, "Epilogue", en: OLÁSOLO, Héctor, The criminal responsability of senior political and military leaders as principals to international crimes, Oxford: Hart Publishers, 2009, pp. 331-336, p. 335.

${ }^{34}$ AMBOS, Kai, “Joint Criminal Enterprise and Command Responsibility", Journal of International Criminal Justice, Vol. 5 (2007), pp. 159-183, p. 168.
} 
Polít. crim. Vol. 8, No 16 (Diciembre 2013), Art. 1, pp. 363-385.

[http://www.politicacriminal.cl/Vol_08/n_16/Vol8N16A1.pdf]

complementario del Estatuto de Roma frente de las jurisdicciones locales (Art. 17), cuya implementación del Estatuto no está condicionada por la adopción de una posición teórica $a$ priori, sino principalmente por el texto del mismo y por los principios generales de su propia legislación. En este sentido, la diferenciación entre distintos tribunales internacionales puede producir perplejidad en ciertos casos, si simultáneamente se aplican diferentes modos o formas de responsabilidad individual en hechos colectivos (en todo caso, generalmente para llegar al mismo resultado), pero no va a producir la sustitución de todo el Derecho penal internacional por las interpretaciones que se ofrezcan del Estatuto de Roma. $^{35}$

Es más, por mucho que no se acepten como reglas de imputación en el Estatuto de Roma la conspiración y la pertenencia a una organización criminal, ello no altera el hecho de que existen en el Derecho internacional formas de responsabilidad colectiva e individual por la pertenencia a grupos y organizaciones declarados criminales, y no sólo en la forma moderna de la Joint Criminal Enterprise (si es cierto que ella recoge una regla de derecho consuetudinario), sino también en la forma tradicional de la conspiración y la pertenencia a una organización criminal como lo disponen los Arts. 6 y 10 de la Carta del Tribunal Militar Internacional de Núremberg, cuyos principios y jurisprudencia fueron confirmados como pertenecientes a los principios del Derecho internacional por la Resolución 95(I) de la Asamblea General de las Naciones Unidas, con fecha 11 de diciembre de 1946. Y dado que al menos la conspiración para cometer genocidio es claramente un crimen bajo el Derecho internacional, según el Art. III b) de la Convención respectiva, se debe aplicar a su respecto lo dispuesto en el Art. 10 del Estatuto de Roma, donde, tras definirse los crímenes bajo su competencia ( in incluir la conspiración para cometer genocidio), se establece que

“Art.10. Nada de lo dispuesto en la presente parte se interpretará en el sentido de que limite o menoscabe de alguna manera las normas existentes o en desarrollo del derecho internacional para fines distintos del presente Estatuto."

Sin embargo, no deja de ser cierto que el Estatuto de Roma sólo contempla expresamente una forma híbrida de responsabilidad individual por "contribución a un grupo", en su Art. 25.3.d), tomada casi literalmente del Art. 2.3.c) del Convenio Internacional para la Represión de Atentados Terroristas con Bombas, dada la resistencia de algunos delegados para aceptar la conspiracy tal cual se entiende en el common law. ${ }^{36}$ Según la redacción oficial del Estatuto en español, una persona puede ser individualmente responsable cuando:

“d) Contribuya de algún modo en la comisión o tentativa de comisión del crimen por un grupo de personas que tengan una finalidad común. La contribución deberá ser intencional y se hará:

i) Con el propósito de llevar a cabo la actividad o propósito delictivo del grupo, cuando una u otro entrañe la comisión de un crimen de la competencia de la Corte; o ii) A sabiendas de que el grupo tiene la intención de cometer el crimen."

\footnotetext{
${ }^{35}$ MATUS A., Jean Pierre, La transformación, cit. nota no 32, pp. 141 y ss.

${ }^{36}$ AMBOS, Kai, Internationales Strafrecht, $3^{\mathrm{a}}$ Ed., München: C.H. Beck, 2011, pp. 170 y ss.
} 
MATUS, Jean Pierre. "Las formas de responsabilidad criminal por el hecho colectivo en el Derecho internacional y en el derecho interno chileno conforme a la Ley $\mathrm{N}^{\circ} 20.537$ '.

Es interesante notar que la literalidad del texto, evitando el castigo del mero acuerdo de actuación común, establece objetivamente un supuesto de responsabilidad por el hecho colectivo respecto del cual el responsable no tiene "dominio" alguno. No se requiere que el que contribuya pertenezca al grupo ni se especifica el modo de la contribución. Naturalmente, si pertenece al grupo la imputación se facilitará, pero no es ese un requisito del texto del Estatuto. Tampoco se requiere que el grupo consienta expresamente la contribución, aunque la relación de causalidad que supone el "contribuir" supone su aceptación al menos tácita. Desde el punto de vista subjetivo, no se exige la intención de cometer el crimen que es el designio común del grupo, sino únicamente, la actividad del grupo, siempre que ésta "envuelva" la comisión de un crimen de competencia de la Corte; o que se sepa que el grupo tiene la intención de cometerlo. Los ejemplos que se ofrecen son los de la provisión de armamento, financiamiento y otras formas de contribución indirecta al crimen.

La doctrina alemana, siguiendo su esquema diferenciador, tiende a considerar este supuesto un caso más bien de participación en el hecho ajeno que de autoría, ${ }^{38} \sin$ alcanzar a percibir que no se trata de la contribución a la conducta de otro, sino a la realización del designio común de un grupo, esto es, de una responsabilidad por un hecho colectivo que no es asimilable sin más a la colaboración en un hecho ajeno individual.

Es más, el presupuesto de hecho de la regla comentada no parece alejarse demasiado de un caso límite de conspiracy que expone Samaha: un juez que, conociendo la conspiración para matar a un colega, intercepta la carta que le advierte de ella, fue sancionado a título de conspiración para el asesinato por su auxilio a los conspiradores, aunque ellos no tuvieron conocimiento del mismo. ${ }^{39}$ Aquí, es claro que si se reescribe el supuesto de hecho de conformidad con el Art. 25.3.d) del Estatuto de Roma se puede decir que se ha contribuido a la comisión de un delito por parte de un grupo de personas que tienen una finalidad común (asesinar a un juez), de algún modo que no es su comisión (interceptando una carta) y ello se ha hecho a sabiendas que el grupo tiene la intención de cometer el crimen que se trata (lo que el juez condenado sabía). Lo extraordinario de esta similitud es que ella implica que los casos más comunes de conspiracy no estarían cubiertos por el Estatuto, pero sí aquellos extraordinarios donde su extensión se admite aún sin acuerdo para perpetrar directamente el crimen.

\section{3. ¿Complementariedad de la regulación nacional de la responsabilidad individual por el hecho colectivo en relación con las reglas del derecho internacional?}

Como hemos dicho, la ley $\mathrm{N}^{\circ} 20.357$ estableció como reglas comunes para los crímenes de lesa humanidad y genocidio su sanción en caso de conspiración, con una pena reducida en dos grados (Art. 14), y la de la asociación ilícita para cometerlos (Art. 16). Además, se contemplan las formas generales de coautoría (Art. $15 \mathrm{~N}^{\circ} 1$ y 3 ) y se reconoce doctrinal y

\footnotetext{
37 SATZGER, Helmuth, Internationales und Europäisches Strafrecht, 4ª Ed., Baden-Baden (Alemania): Nomos, 2010, p. 287.

${ }^{38}$ AMBOS, Internationales, cit. nota $\mathrm{n}^{\circ} 36, \mathrm{p} .171$.

${ }^{39}$ SAMAHA, Joel, Criminal Law, 4ª Ed., New York: West Group, 1993, p. 208.
} 
Polít. crim. Vol. 8, № 16 (Diciembre 2013), Art. 1, pp. 363-385.

[http://www.politicacriminal.cl/Vol_08/n_16/Vol8N16A1.pdf]

jurisprudencialmente la autoría mediata. La pregunta que sigue es si con tales previsiones se cubren o no todos los casos de responsabilidad individual por el hecho colectivo contemplados en el Derecho internacional.

Si hemos de estarnos a la interpretación del Art. 25.3.a del Estatuto de Roma que entiende que cometer un crimen "con otro o por conducto de otro" equivaldrían a los conceptos de coautoría y autoría mediata, de conformidad con la doctrina del dominio del hecho elaborada por Claus Roxin, la respuesta es sencilla: sí, si se acepta también que entre nosotros los conceptos de coautoría (Art. $15 \mathrm{~N}^{\circ} 1$ y 3) y autoría mediata corresponden a los de dicha doctrina, lo cual es así, según nuestra doctrina y jurisprudencia mayoritarias. Más dificultades se nos presentan a la hora de comprobar si la remisión del Art. 14 de la Ley $\mathrm{N}^{\circ} 20.357$ al castigo de la conspiración para cometer genocidio es complementaria con la disposición del Art. III b) de la Convención respectiva.

En síntesis, en nuestro Derecho, conforme dispone el inc. $2^{\circ}$ del art. $8^{\circ} \mathrm{CP}$, "la conspiración existe cuando dos o más personas se conciertan para la ejecución del crimen o simple delito". Se conspira para ejecutar un delito determinado, y al igual que en el caso de la proposición, el castigo por la ejecución de ese delito impide su sanción también a título de conspiración. Tampoco hay inducción a la conspiración, complicidad, tentativa ni encubrimiento de la misma, ya que se trata de un anticipo de la punibilidad especialmente regulado: puesto que la conspiración requiere concierto para la ejecución de un delito, todos los partícipes en ella deberían tomar parte en la ejecución del delito para que se conspira, excluyéndose así la llamada "conspiración en cadena" y, particularmente, la conspiración para la inducción, puesto que la inducción no es un acto de ejecución. En cuanto a la naturaleza del acuerdo, se requiere un acuerdo acerca del lugar, modo y tiempo de ejecutar un delito determinado y la decisión seria de ponerlo por obra, aunque no se requiere un acuerdo acerca de todos y cada uno de los detalles de su ejecución. Además, la conspiración supone concierto para cometer, esto es, coejecutar, un crimen o simple delito, en el sentido del art. $15 \mathrm{~N}^{\mathrm{o}} 1 \mathrm{CP}$, lo que significa, básicamente, división del trabajo entre personas de igual rango. Finalmente, el acuerdo para cooperar en la comisión de un delito de manera subordinada, en un sentido diferente al señalado, no constituye conspiración (ej.: solicitar a otro que lo lleve al lugar donde se cometerá el crimen, en cuya ejecución ese otro no tomará parte). ${ }^{40}$

Buena parte de estas exigencias no se predican, sin embargo, de la conspiracy anglosajona que sirve de fundamento a la conspiracy del Art. III b) de la Convención para la Prevención y Sanción del Crimen de Genocidio.

En efecto, según el Black's Law Dictionary, conspiracy es un delito independiente del que se pretende cometer, cuya definición objetiva es difícil debido a su dependencia con el delito a que se dirige y que básicamente tiene una "configuración mental", consistente en

\footnotetext{
${ }^{40}$ POLITOFF / MATUS / RAMÍREZ, Lecciones $P G$, cit. nota no 7, p. 392.
} 
MATUS, Jean Pierre. "Las formas de responsabilidad criminal por el hecho colectivo en el Derecho internacional y en el derecho interno chileno conforme a la Ley N²0.537”.

\begin{abstract}
"An agreement by two or more persons to commit an unlawful act, coupled with an intent to achieve the agreement's, and (in most states) action or conduct that furthers the agreement; a combination for unlawful purpose". ${ }^{41}$
\end{abstract}

Samaha nos indica que dicho acuerdo (agreement) no tiene por qué ser escrito, en muchas jurisdicciones se acepta que sea sólo para "ayudar" en la perpetración y no necesariamente para perpetrar, e incluso que es posible una conspiración sin consentimiento, cuando se actúa colaborando en un designio común ya decido por otros, como ya lo hemos señalado. ${ }^{42}$ Además, como señala Politoff, también se castigan, en el derecho anglosajón, las wheelconspiracies y las chainconspiracies, esto es, las "conspiraciones en cadena" o conspiración para conspirar o para inducir a otro a cometer un delito. ${ }^{43}$

Todos estos supuestos serían impunes entre nosotros, lo mismo que el caso extraordinario del Art. 25.3.d) del Estatuto de Roma, en relación con la conspiración de otros.

En cambio, respecto de la membresía en una organización criminal, que no se encuentra establecida en ningún Tratado o Estatuto relativo a los crímenes internacionales posteriores a Núremberg, la situación es la inversa. Y ello, no sólo por el creciente interés de los Estados en regular otros casos de criminalidad organizada transnacional, como los relativos al tráfico de drogas, según sugiere Bassiouni, ${ }^{44}$ sino por la propia estructura de nuestro delito de asociación ilícita contemplado en el Art. 292 del Código penal desde su promulgación en 1874, y a cuya regulación remite el Art. 15 de la Ley N²0.357, al menos respecto de los delitos de genocidio y contra la humanidad.

En efecto, nuestra regulación del delito de asociación ilícita parece comprender sin dificultad la exigencia mínima de los casos que se planteaban en la jurisprudencia de Núremberg, esto es, el ingreso voluntario con conocimiento del designio criminal común, ya que el artículo 292 del Código penal describe como delito la asociación ilícita por el solo hecho de organizarse y el Art. 294 sanciona a "cualesquiera" "individuos que hubieran tomado parte en la asociación". La limitación jurisprudencial y doctrinal en el sentido de que debe distinguirse la asociación ilícita de una mera conspiración en atención a la naturaleza de la organización no afecta esta conclusión. En efecto, afirmar que la asociación ilícita requiere que el acuerdo o concierto sea para cometer no uno sino varios delitos en el seno de una organización con cierta estructura jerárquica y con un carácter permanente $^{45}$ refleja el entendimiento que de las agrupaciones delictivas se apreció en Núremberg, si se atiene a la naturaleza de las organizaciones condenadas tras la segunda

\footnotetext{
${ }^{41}$ GARNER, Bryan A., Black's Law Dictionary, 8a Ed., Estados Unidos: West Group, 2004, p. 329.

${ }^{42}$ SAMAHA, Criminal Law, cit. nota ${ }^{\circ} 39$.

${ }^{43}$ POLITOFF L., Sergio, "La conspiración para cometer delitos previstos en la Ley sobre Tráfico Ilícito de Estupefacientes", en: POLITOFF L., Sergio; MATUS A., Jean Pierre (Coords.), El tratamiento penal del tráfico ilícito de estupefacientes. Estudios de dogmática y jurisprudencia, Santiago: Ed. Conosur, 1999, pp. 89-109, pp.93-96.

${ }^{44}$ BASSIOUNI, Introduction, cit. nota ${ }^{\circ}$ 24, p. 84. Sobre los delitos de carácter transnacional y la influencia de los tratados celebrados a su respecto en la legislación local, véase MATUS A., Jean Pierre, "La política criminal de los tratados internacionales", Derecho penal contemporáneo, $\mathrm{N}^{\circ} 19$ (2007), pp. 71-100.

${ }^{45}$ ETCHEBERRY, Derecho penal IV, cit. nota $\mathrm{n}^{\mathrm{o}} 10$, p. 317.
} 


\section{Polít. crim. Vol. 8, № 16 (Diciembre 2013), Art. 1, pp. 363-385. [http://www.politicacriminal.cl/Vol_08/n_16/Vol8N16A1.pdf]}

guerra mundial (los dirigentes del partido nazi, la Gestapo, la SS y la SD). Lo discutible actualmente no es que en tales casos pueda castigarse por la pertenencia a una organización, ${ }^{46}$ sino si es esa la clase de organizaciones criminales que existen hoy en día, donde la organización horizontal y por franquiciamiento parece ir ganando terreno tanto en lo lícito como en lo ilícito. Y por eso es que la ausencia de criterios para configurar esta clase de organizaciones, donde la estructura jerárquica e incluso la permanencia no son elementos siempre presentes ni mucho menos de manera conjunta, pueda conducir a perplejidades, a pesar de que, como hemos dicho, determinada la existencia de una organización criminal, en Chile es punible la sola pertenencia a la misma, si se conocen sus objetivos.

Es más, existiendo una asociación ilícita, el Art. 294 del Código penal contiene una regla que cumple una función similar a la del Art. 25.3.d) del Estatuto de Roma (el cual, sin embargo, no se limita a las asociaciones ilícitas, sino que aplica, en principio, a todo grupo con un designio común, esto es, incluyendo a un grupo de conspiradores), especificando tanto la exigencia subjetiva como las formas de contribución con la asociación que son punibles para "los que a sabiendas y voluntariamente le hubieren suministrado [a los asociación ilícita] medios e instrumentos para cometer los crímenes o simples delitos, alojamiento, escondite o lugar de reunión”.

Y aún es posible reconducir al Art. 295 bis un caso especial del que colabora sin consentimiento de la asociación, cuando dicha colaboración consiste en omitir denunciar su existencia, habiendo tenido noticias verosímiles de sus planes o actividades.

Por otra parte, el castigo independiente que se prevé para los delitos que se cometen con motivo u ocasión de la asociación, de conformidad con el Art. 294bis, a pesar de las dudas

\footnotetext{
${ }^{46}$ Una fundamentación de este castigo, desde un punto de vista funcionalista que admite la existencia fáctica del carácter peligroso de una asociación ilícita y la normativa del hecho colectivo como expresión de una "magnitud social autónoma", puede verse en CANCIO M., Manuel, "El injusto de los delitos de organización: peligro y significado", ICADE, Revista cuatrimestral de las Facultades de Derecho y Ciencias Económicas y Empresariales, $\mathrm{N}^{\circ} 74$ (2008), pp. 245-287. Según Cancio, "las organizaciones sólo se perciben en lo que se refiere al incremento de peligrosidad que suponen frente a autores individuales o concertados de modo esporádico, es decir, su cualidad de dispositivos de multiplicación de los distintos factores de riesgo respecto de los bienes jurídicos individuales afectados por las infracciones cometidas a través de la organización", y "con toda certeza, esta especial peligrosidad de las organizaciones delictivas es un punto de vista de gran relevancia para su comprensión dogmática" (p. 268). Sin embargo, agrega, es un punto de vista insuficiente para su acaba comprensión: "Al margen de la intensificación de la peligrosidad a través de la dinámica de grupo, un actor colectivo entra en escena: la organización emerge como magnitud social autónoma" (p. 268). Si ello es así, los hechos del ente colectivo (empezando por su existencia) deben vincularse de alguna manera al individuo para que se les puedan imputar como un todo, a pesar de que él sólo ha realizado una aportación parcial. Esta aportación parcial que justificaría la imputación del hecho colectivo al individuo es, según Cancio, precisamente su pertenencia al colectivo. Y como se sostiene en este trabajo, afirma Cancio: "En este sentido, en este ámbito surge espontáneamente un paralelismo hacia la situación en la codelincuencia, y, en particular, respecto de la coautoría: en cierto modo, se produce aquí una condensación, una cualificación, respecto de una actividad en régimen de coautoría; se accede así a un plano superior, precisamente, al plano de la actuación colectiva. No hay en ello una transferencia injustificada de responsabilidad. La aportación personal del autor individual puede ser aprehendida jurídico-penalmente (de modo indirecto y estandarizado) a través de la prestación de organización hecha a título de miembro del colectivo" (p. 272).
} 
MATUS, Jean Pierre. "Las formas de responsabilidad criminal por el hecho colectivo en el Derecho internacional y en el derecho interno chileno conforme a la Ley $\mathrm{N}^{\circ} 20.537$ '.

que ello genera desde el punto de vista de su tratamiento concursal, ${ }^{47}$ es un elemento que asemeja nuestra asociación ilícita con la conspiracy, en casos que el designio común se comparta en el seno de una organización más o menos permanente y jerarquizada.

Siguiendo esta línea, si se puede concebir el designio común como el acuerdo que constituye la asociación ilícita, a ella podrían reconducirse en nuestro sistema todos los supuestos de JCE, ya que la actuación posterior criminal no es requisito de ésta (como tampoco de la conspiración), siempre que tal designio se exprese en una organización más o menos permanente y jerarquizada.

Sin embargo, ello no es así en todos los casos, pues las limitaciones y exigencias de nuestras conspiraciones y asociaciones punibles difieren en aspectos importantes de las exigencias de una JCE.

En primer lugar, en cuando a su alcance, está establecido que una JCE puede ser la fuente de imputación en cualquiera de los crímenes comprendidos en los Estatutos de los Tribunales ad hoc, ${ }^{48}$ así como el Art. 25.3.d) del Estatuto de Roma se aplica a todos los crímenes de competencia de la Corte Penal Internacional. Sin embargo, la ley $N^{\circ} 20.357$ ha limitado el castigo de la conspiración y la asociación ilícita exclusivamente a crímenes de lesa humanidad y genocidio, dejando fuera los crímenes de guerra. Esta limitación general se predica también respecto de la extensión del castigo por la conspiración y pertenencia a una organización criminal de conformidad con el Estatuto del Tribunal Militar Internacional de Núremberg.

En segundo término, no se puede afirmar que entre nosotros pueda admitirse que una asociación ilícita se baste con un acuerdo que sólo "comprenda o implique" (involves) la comisión de un crimen, pues se dice que "la asociación debe haber tenido por objeto la comisión de multiplicidad de delitos, y no de uno solo". ${ }^{9}$ En estos casos sólo podría reconducirse el hecho a una conspiración, pero aquí nos encontraríamos con la dificultad de que una conspiración, entre nosotros, requiere el acuerdo para cometer un delito determinado y no sólo una actividad que implique la comisión de un crimen, como es característico de la JCE III o extendida, donde los crímenes que se cometen no se han acordado ni expresa ni implícitamente, sino que se extienden a hechos que van más allá del acuerdo, pero que son una consecuencia natural y previsible ("posible") del plan acordado. $^{50}$

\footnotetext{
${ }^{47}$ La cuestión es si se aplica en todo caso el régimen general de acumulación material del Art. 74 del Código penal como propone Grisolía ("El delito de asociación ilícita", cit. nota $n^{\circ} 10$, p. 86) o puede estimarse la relación entre el delito de asociación ilícita y los que se comenten con motivo u ocasión de su organización como una relación de medio a fin, habilitando la eventual rebaja penológica de la regla (no siempre) más favorable del concurso medial del Art. 75, como proponen Carnevali y Fuentes, citando una jurisprudencia de la Corte Suprema en este sentido (CARNEVALI R., Raúl; FUENTES F., Hernán, "Informe jurídico sobre la eventual aplicación del delito de asociación ilícita establecido en el art. 16 de la Ley $\mathrm{N}^{\circ} 20.000$ ", Política Criminal, Vol. 3, ํ6 6 (2008), D1, p.7 [http://www.politicacriminal.cl/n_06/d_1_6.pdf].)

${ }^{48}$ ICTY, Prosecutor $v$. Tadic, cit. nota $\mathrm{n}^{\circ} 27$, par. 188.

${ }^{49}$ ETCHEBERRY, Derecho penal $I V$, cit. nota $\mathrm{n}^{\circ} 10$.

${ }^{50}$ ICTY, Prosecutor v. Blaskic, Caso No IT-95-14-A, 29.07.2004, párr. 33.
} 
Polít. crim. Vol. 8, № 16 (Diciembre 2013), Art. 1, pp. 363-385.

[http://www.politicacriminal.cl/Vol_08/n_16/Vol8N16A1.pdf]

Tercero, de conformidad con la jurisprudencia de los tribunales ad hoc, al igual que en una asociación ilícita, una JCE, aunque normalmente está compuesta de varias personas, "puede existir allí donde dos o más personas participen en un emprendimiento criminal común", 51 pero no requiere que esas personas estén organizadas en una suerte de "estructura" militar, política o administrativa, ${ }^{52}$ permanente y jerarquizada, como se exige para nuestra asociación ilícita.

Y aunque se podría decir que, a falta de una asociación ilícita bien puede recurrirse a la conspiración, aparecen de nuevo aquí las diferencias de nuestra regulación con la conspiracy anglosajona que limitan su aplicación: de conformidad con lo antes expuesto, una conspiración en Chile exige un acuerdo para co-ejecutar un delito determinado. En cambio, en una JCE lo que se debe probar es "la existencia de un plan, propósito o designio común que comprende o implica la comisión de un crimen". ${ }^{53}$ Es decir, dicho acuerdo no exige en todos los casos una determinación precisa del crimen a cometer ni una posición de relativa igualdad funcional entre los que lo adoptan. Es más, proveniente de la tradición anglosajona de la conspiracy, ese designio común puede existir con independencia y anterioridad del hecho de que alguien se sume al mismo. Así, aunque para los casos de JCE I y JCE III parece exigirse que el plan común suponga un acuerdo en relación a la comisión de un "crimen particular", 54 ello no se exige en los casos de JCE II o sistemática. Allí, la existencia misma del sistema de maltratos o torturas se identifica con la del plan o propósito común y no se exige la prueba de una aceptación o acuerdo formal o informal entre quienes lo llevan a efecto, sino únicamente el conocimiento de que tal sistema de maltratos y torturas existe y que está de acuerdo en participar en su operación. ${ }^{55}$ Entre nosotros, este supuesto sólo podría reconducirse a la figura de colaboración con una asociación ilícita del Art. 294, si la forma de colaboración es una de las allí indicadas y se prueba la existencia de la asociación entre quienes han puesto en marcha el sistema de maltratos y torturas.

Por otra parte, como el Estatuto del Tribunal Penal Internacional para la ex Yugoslavia no contempla como formas de responsabilidad penal la conspiracy (salvo para el caso del crimen de genocidio) ni la pertenencia a una organización criminal (lo que sí es punible en Chile, con las diferencias ya expuestas, a través de la conspiración y la asociación ilícita), todas las formas de JCE exigen un elemento material adicional para poder acusar a una persona a título de comisión de un crimen de competencia de ese tribunal: la participación en la puesta en ejecución del designio común. Según el ICTY:

"Hay varias maneras en las cuales una persona puede participar en una empresa criminal conjunta: (i) cometiendo personalmente el delito acordado como autor principal, (ii) ayudando al autor principal en la comisión del delito acordado como co-

\footnotetext{
51 ICTY, Prosecutor v. Kvacka, Radic, Zigic y Prcac, Caso No IT-98.30/1-A, 28-02-2005, párr. 307

${ }^{52}$ ICTY, Prosecutor v. Stakic, Caso N IT-97-24-A, 22.03.2006, párr. 64

${ }^{53}$ ICTY, Prosecutor v. Tadic, cit. nota $\mathrm{n}^{\circ} 27$, par. 227. Los términos en inglés son "existence of a common plan, design or purpose which amounts to or involves the commission of a crime provided for in the Statute".

${ }^{54}$ ICTY, Prosecutor v. Simic, Tadic y Zaric, Caso N IT-95-9-T, 17.10.2003, párr. 158: “arrangement or understanding amounting to or involving an agreement between two or more persons that a particular crime will be committed".

${ }^{55}$ ICTY, Prosecutor v. Krnojelac, Caso N IT-97-25-A, 17.09.2005, párr. 96.
} 
MATUS, Jean Pierre. "Las formas de responsabilidad criminal por el hecho colectivo en el Derecho internacional y en el derecho interno chileno conforme a la Ley N²0.537”.

perpetrador, i. e. facilitando la comisión del crimen con la intención de llevar a cabo la empresa, o (iii) actuando dentro de un sistema particular en el cual se comete el delito, en razón de que el acusado tenga una posición de autoridad u otra función y conozca la naturaleza de ese sistema y tenga la intención de que ese sistema cumpla sus objetivos." 56

Del numeral iii) se ha derivado la posibilidad de acusar a título de comisión de los crímenes de competencia de la ICTY a los líderes y dirigentes que, lejos del campo de operaciones, organizaban, financiaban o contribuían materialmente a las tropas, bandas y grupos armados que ejecutaban las matanzas y atrocidades que se consideraban necesarias para los planes de limpieza étnica. ${ }^{57}$

Entre nosotros, esta forma de responsabilidad individual por el hecho colectivo podría encontrarse en el Art. 294bis del Código penal, si se puede acreditar el requisito base para su aplicación, esto es, la existencia de una asociación ilícita. En efecto, dicha disposición establece:

“Art. 294 bis. Las penas de los artículos 293 y 294 se impondrán sin perjuicio de las que correspondan, por los crímenes o simples delitos cometidos con motivo y ocasión de tales actividades".

Si el sentido de la regla supone algo más que una regla concursal, ${ }^{58}$ ese algo más no es otra cosa que imputar a los jefes y provocadores (Art. 293) y a cualesquiera otros individuos que hubieren tomado parte en la asociación (Art. 294) los delitos cometidos por ésta, como hecho colectivo, a través de uno o algunos de sus miembros en cumplimiento de sus fines, esto es, con motivo u ocasión de tales actividades, esto es, de haberse asociado ilícitamente, entonces a la exigencia objetiva y subjetiva de la pertenencia a la organización compartiendo sus fines (lo que habilita el castigo penal "por el solo hecho de organizarse") deberían sumarse exigencias de la misma índole en relación con esos delitos cometidos materialmente por otros miembros de la organización. Aquí, en principio, lo objetivo es precisamente que esos delitos puedan verse como la materialización o consecuencia natural o previsible de las finalidades de la organización y el aspecto subjetivo debiera vincularse precisamente a ello, esto es, al hecho que pueda ser previsible para el miembro de la organización a quien se le imputa ese hecho colectivo que, de su contribución a la asociación ilícita se sigue la consecuencia natural y previsible de la comisión material de esos delitos por otros miembros de la organización. Desde esta perspectiva aparece con claridad la ventaja que puede obtenerse de la construcción de la JCE III si se considera que ella implica no sólo una extensión de la JCE I, sino también una limitación a la sanción por

\footnotetext{
${ }^{56}$ ICTY, Prosecutor v. Blagojevic y Jokic, Caso No IT-02-60-T, 01.09.2004, párr. 702: "There are various ways in which a person may participate in a joint criminal enterprise: $(i)$ by personally committing the agreed crime as principal offender; (ii) by assisting the principal offender in the commission of the agreed crime as a co-perpetrator, i. e. facilitating the commission of the crime whit the intent to carry out the enterprise; or (iii) by acting in furtherance of a particular system in which the crime is committed by reason of the accused's position of authority or function and with knowledge of the nature of that system and intent to further that system."

${ }^{57}$ Véase, por todos, ICTY, Prosecutor v. Krstic, Caso No IT-98-33-T, 2.08.2001.

${ }^{58}$ Véase nota $n^{\circ} 47$.
} 
la "mera pertenencia" en casos de "excesos" de algunos miembros de la asociación: los delitos que constituyen el designio común, en este caso, el objeto para el cual se han asociado los responsables, no se consideran un "exceso", pero, además, sólo podrían ser imputables al resto de los miembros de la asociación si son consecuencia natural o previsible de la actividad de la asociación a la cual ellos contribuyen, esto es, si efectivamente se han cometido "con motivo u ocasión" de dicha asociación y los miembros de la misma al menos pudieron preverlo como consecuencia de sus actividades, haciéndose así responsables de manera individual del hecho colectivo materializado por los otros miembros de la asociación.

Como se ha dicho, según la doctrina adoptada por la Corte Penal Internacional, todos estos casos se encontrarían de alguna manera comprendidos en el Art. 25.3.a) del Estatuto de la Corte Penal Internacional, a través de la sanción de las formas de comisión que se señalan, a saber, cometer el crimen "con otro o por conducto de otro" ("jointly with another or through another person”), entendiendo estas expresiones según la doctrina del dominio del hecho, en la forma expuesta por Roxin.

La diferencia con la JCE estaría fundamentalmente en los supuestos de JCE III, donde con independencia de la posición del partícipe en el sistema, se podría considerar su intervención como autoridad o en otra función que permita lograr el objetivo una forma de comisión de crímenes que no se encuentran dentro del plan común, pero que son una consecuencia natural, previsible o posible de su ejecución.

Según Kai Ambos, no es claro que tales supuestos puedan reconducirse a los casos de autoría mediata reconocidos en la doctrina y su legitimidad sería dudosa, desde el momento que parecería una suerte de imputación por la pertenencia a un grupo, difícilmente conciliable con el principio de culpabilidad. ${ }^{59}$

Al respecto hay que decir lo siguiente: primero, que no parece claro que la atribución de responsabilidad por un hecho que es consecuencia natural o previsible de otro infrinja el principio de culpabilidad, si se entiende éste, para estos efectos, como la exigencia de una mínima relación entre la subjetividad o estado mental del imputado con la realización del hecho que se le imputa. Esta clase de relación subjetiva con un hecho "previsible" o "consecuencia natural" de otro es la que se predica en nuestro sistema cuando se discurre acerca de la responsabilidad a título de dolo de las consecuencias necesarias, dolo eventual y culpa con representación ${ }^{60}$. Naturalmente, si se afirma que tratándose de crímenes contemplados en el Estatuto de Roma o en cualquier otra disposición positiva sólo se admite su comisión con intención o dolo directo, debe rechazarse al menos la posibilidad de su imputación a título de dolo eventual o culpa. Pero ello no significa que exista una violación del principio de culpabilidad al admitirlos, sino sólo que el Estatuto de Roma no contemplaría estas formas de responsabilidad por los delitos que contempla.

\footnotetext{
${ }^{59}$ AMBOS, “Joint Criminal Enterprise”, cit. nota al pie n 34, p. 174.

${ }^{60}$ Sobre el contenido de estas discusiones, véase, por todos, POLITOFF L. Sergio, Derecho penal, T. I., $2^{\mathrm{a}}$ Ed., Santiago: Ed. Conosur, 2000, pp. 362-372 y 375-380.
} 
MATUS, Jean Pierre. "Las formas de responsabilidad criminal por el hecho colectivo en el Derecho internacional y en el derecho interno chileno conforme a la Ley $\mathrm{N}^{\circ} 20.537$ '.

Por otra parte, según Cassese -uno de los jueces redactores del fallo Tadic-, quien reconoce que no debe subestimarse el peligro de castigar a alguien sólo por estar asociado de alguna manera a quien ha cometido el delito, tampoco la práctica de los Tribunales ad hoc en aplicación de la JCE habría llegado al punto de sancionar por la "mera pertenencia", "declinando atribuir responsabilidad sobre la base de esta doctrina cuando la contribución del acusado al crimen ha sido muy remota o su mens rea no ha podido establecerse". ${ }^{61}$

Y finalmente, pero no menos relevante en la discusión, hay que decir que la sanción por la "mera pertenencia" voluntaria a una organización criminal cuyos fines se conocen y comparten no es desconocida en el Derecho internacional, como lo demuestra la Carta y la Jurisprudencia de Núremberg, ${ }^{62}$ ni tampoco en el derecho local, como lo demuestra la sanción por el delito de asociación ilícita, prevista no sólo en Chile, sino en buena parte de los ordenamientos occidentales desde la codificación decimonónica, incluso en Alemania. ${ }^{63}$

\section{Conclusiones.}

En síntesis, respecto de las formas de responsabilidad individual por el hecho colectivo, en Chile, los dos dispositivos penales que la regulan y a los que se remiten los arts. 14 y 15 de la Ley $\mathrm{N}^{\circ} 20.357$ para los casos genocidio y delitos de lesa humanidad, la conspiración y la asociación ilícita, permiten abarcar una serie de supuestos de responsabilidad penal individual por el hecho colectivo desarrollados en el Derecho penal internacional, pero no todos ellos, en buena parte debido a que, en primer lugar, sólo aparentemente forman un continuo, dejando espacios de punibilidad desconcertantes; y en segundo término, a que la formulación local de la conspiración no necesariamente permite comprender todos los casos derivados de la conspiracy anglosajona, incluyendo la doctrina de la Joint Criminal Enterprise. Algunos de estos vacíos, pero no todos, pueden llenarse si se acepta que la regulación de la responsabilidad individual por el hecho colectivo ha de seguir vinculada a la teoría del dominio del hecho, según la tesis desarrollada por Roxin, que incluye algunos casos de responsabilidad por el hecho colectivo en los supuestos de coautoría y autoría mediata.

Finalmente, cabe señalar que quizás la principal crítica que tiene el carácter expansivo de la doctrina de la JCE III a líderes y otros miembros de organizaciones cuyo propósito común

\footnotetext{
${ }^{61}$ CASSESE, Antonio; ACQUAVIVA, Guido; FAN, Mary; WHITING, Alex, International Criminal Law. Cases \& Commentary, New York: Oxford University Press, 2011, pp. 334 y ss.

62 Sin embargo, ya se ha mencionado que esta forma de responsabilidad no parece haber alcanzado independientemente el status de norma de derecho consuetudinario, como ha remarcado también la Corte Suprema de los Estados Unidos de América (Hamdam v. Rumsfeld, 548 U.S. 557 (2006), 29.06.2006).

${ }^{63}$ Como expresamente señala el $\$ 129$ del Código penal alemán, al castigar a quien establezca o sea miembro de una asociación cuyas finalidades o actividades estén dirigidas a la comisión de delitos ("(1) Wer eine Vereinigung gründet, deren Zwecke oder deren Tätigkeit darauf gerichtet sind, Straftaten zu begehen, oder wer sich an einer solchen Vereinigung als Mitglied beteiligt, für sie um Mitglieder oder Unterstützer wirbt oder sie unterstützt”). El parágrafo contempla, además, disposiciones que permiten no imponer la pena o imponer una medida alternativa al mero partícipe, pero al mismo tiempo, agravan la de sus dirigentes y "hombres de atrás". Sobre los detalles de la regulación alemana, véase LENCKNER, Theodor, "Kommentar zur §129 StGB”, en: SCHÖNCKE, Adolf; SCHRÖDER, Horst, Strafgesetzbuch Kommentar, 24 ${ }^{\mathrm{a}}$ Ed., München: C.H. Beck, 1991, pp. 1117-1129.
} 
Polít. crim. Vol. 8, № 16 (Diciembre 2013), Art. 1, pp. 363-385.

[http://www.politicacriminal.cl/Vol_08/n_16/Vol8N16A1.pdf]

tiene como consecuencia natural y previsible la comisión de crímenes bajo el derecho internacional -crítica que también es extensible a la teoría de la autoría mediata transportada sin más desde el derecho local alemán al internacional-, es que, probablemente en tales casos, una aplicación directa de las otras formas de responsabilidad individual que contemplan tanto el Derecho penal internacional como los ordenamientos locales (particularmente, la llamada responsabilidad del superior, que la Ley $\mathrm{N}^{\circ} 20.357$ contempla en su Art. 35) podrían ser más apropiadas para describir las conductas de los acusados, probarlas y permitir su condena sin necesidad de recurrir a categorías, conceptos o teorías que no se incluyen expresamente en los estatutos ni en las legislaciones locales. ${ }^{64}$

\section{BIBLIOGRAFÍA CITADA}

AMBOS, Kai, "Epilogue”, en: OLÁSOLO, Héctor, The criminal responsability of senior political and military leaders as principals to international crimes, Oxford: Hart Publishers, 2009, pp. 331-336.

"El primer fallo de la Corte Penal Internacional (Prosecutor v. Lubanga): un análisis integral de las cuestiones jurídicas", InDret 3/2012, pp. 25-37.

"Joint Criminal Enterprise and Command Responsibility", Journal of International Criminal Justice, Vol. 5 (2007), pp. 159-183, p. 168.

, Internationales Strafrecht, 3a. Ed., München: C.H. Beck, 2011, pp. 170 y ss.

ARISTÓTELES, Ética Nicomáquea, Trad. J. Pallí B., Madrid: Gredos, 2000,

BASSIOUNI, M. Cherif, Introduction to International Criminal Law, Nueva York: Transnational Publishers, 2003.

BENTEKAS, Ilias, International Criminal Law, 4ª Ed., Oxford: Hart Publishers, 2010.

BIBLIOTECA DEL CONGRESO NACIONAL, Historia de la Ley $N^{\circ} 20.357$.

BOAS, Gideon; BISCHOFF, James; REID, Natalie, International criminal law practitioner library, Vol. I, Cambridge: Elsevier Science Publishers B.V, 2011.

CANCIO M., Manuel, "El injusto de los delitos de organización: peligro y significado", ICADE, Revista cuatrimestral de las Facultades de Derecho y Ciencias Económicas y Empresariales, $\mathrm{N}^{\circ} 74$ (2008), pp. 245-287.

CÁRDENAS A., Claudia y FUENTES T., Ximena, Corte penal internacional y jurisdicciones estatales. El principio de complementariedad, Santiago: Thomson Reuters, 2012.

CÁRDENAS, Claudia, "La implementación de los crímenes de competencia de la Corte Penal Internacional en la Ley $\mathrm{N}^{\circ}$ 20.357, Revista de Derecho (Valdivia), Vol. XXIII, $\mathrm{N}^{\circ} 2$, pp. 23-44.

\footnotetext{
${ }^{64}$ BOAS / BISCHOFF / REID, International Criminal Law, cit. nota $\mathrm{n}^{\circ} 24$, p. 141. La prevención se encuentra ya en el fallo de instancia del caso Brdanin, revertido en cuanto suponía una limitación a la extensión de la JCE, pero no en cuanto al fondo, pues la Cámara de Apelaciones estimó que si bien el acusado, como dirigente del Partido Democrático Serbio (SDS) y de la Región de Krajina formaba parte de una joint criminal enterprise cuyo designio común era la expulsión permanente y forzada de la población bosnia musulmana y bosnia croata del territorio del futuro Estado Bosnio Serbio, no encontró probado que al menos algún miembro de su misma organización haya sido alguno de los que ejecutaron dicho plan en terreno, por la falta de individualización de éstos (ICTY, Prosecutor v. Brdanin, Caso $\mathrm{N}^{\circ}$ IT-99-36-A, 03.04.2007, especialmente párrs. 423-432 y 449).
} 
MATUS, Jean Pierre. "Las formas de responsabilidad criminal por el hecho colectivo en el Derecho internacional y en el derecho interno chileno conforme a la Ley N²0.537”.

CARNEVALI R., Raúl; FUENTES F., Hernán, "Informe jurídico sobre la eventual aplicación del delito de asociación ilícita establecido en el art. 16 de la Ley $\mathrm{N}^{\circ}$ 20.000", en Política Criminal, Vol. 3, $\mathrm{N}^{\circ} 6 \quad$ (2008), D1, p.7 [http://www.politicacriminal.cl/n_06/d_1_6.pdf].)

CASSESE, Antonio; ACQUAVIVA, Guido; FAN, Mary; WHITING, Alex, International Criminal Law. Cases \& Commentary, New York: Oxford University Press, 2011.

CURY U., Enrique, Derecho penal. Parte general, $7^{\mathrm{a}}$ Ed., Santiago: Ed. P. Universidad Católica, 2005.

CURY U., Enrique; MATUS A., Jean Pierre, “Comentario al Art. 15 N¹”, en: POLITOFF/ ORTIZ / MATUS, Texto y comentario del Código penal chileno, T. I, Santiago: Ed. Jurídica de Chile, 2002.

DEL RÍO C., Raimundo, Derecho penal, T. II, Santiago: Ed. Nascimento, 1935. , Derecho penal, T. III, Santiago: Ed. Nascimento, 1935.

ETCHEBERRY, Alfredo, Derecho penal, T. IV, $3^{\text {a }}$ Ed., Santiago: Ed. Jurídica de Chile, 1998.

GARNER, Bryan A., Black's Law Dictionary, 8ª Ed., Estados Unidos: West Group, 2004.

GRISOLÍA C., Francisco, "El delito de asociación ilícita", Revista Chilena de Derecho, Vol. 31 (2004), $\mathrm{N}^{\circ} 1$, pp. 75-88.

GUZMÁN D., José Luis, Estudios y Defensas Penales, Santiago: Legal Publishing, 2005.

HOMERO, Ilíada, Trad. E. Crespo, Madrid: Gredos, 2000.

KÜNSEMÜLlER L., Carlos, "Comentario al Art. 12, 11‥", en: POLITOFF/ ORTIZ / MATUS, Texto y comentario del Código penal chileno, T. I, Santiago: Ed. Jurídica de Chile, 2002.

LABATUT G., Gustavo, Derecho penal, T. II., $7^{\mathrm{a}}$ Ed. actualizada por J. Zenteno, Santiago: Ed. Jurídica de Chile, 1983.

LAEL, Richard L., The Yamashita Precedent. War Crimes and Command Responsibility, Delaware: Wilmington, 1982.

LENCKNER, Theodor, "Kommentar zur §129 StGB”, en: SCHÖNCKE, Adolf; SCHRÖDER, Horst, Strafgesetzbuch Kommentar, 24a Ed., München: C.H. Beck, 1991, pp. 1117-1129.

MATUS A., Jean Pierre, "La política criminal de los tratados internacionales", Derecho penal contemporáneo, $\mathrm{N}^{\circ} 19$ (2007), pp. 71-100. , Evolución histórica de la doctrina penal chilena, desde 1874 hasta nuestros dias, Santiago: Thomson Reuters, 2011. , La transformación de la teoría del delito en el Derecho penal internacional, Barcelona: Atelier, 2008.

, "Sergio Yáñez: obra e influencia. La dogmática chilena actual”, Revista de Derecho (Coquimbo), Vol. 14 (2007), № 1, pp.113-130.

MERA F., Jorge, “La conspiración”, en: COUSO S., Jaime y HERNÁNDEZ B., Héctor, Código penal comentado, Santiago: Thomson Reuters, 2011, pp.173-176.

METTRAUX, Guénaël, The Law of Command Responsibility, Oxford / New York: Oxford University Press, 2009.

NOVOA M., Eduardo, Curso de Derecho penal. Parte general, t. II, $3^{\text {a }}$ Ed., Santiago: Ed. Jurídica de Chile, 2005. 
Polít. crim. Vol. 8, № 16 (Diciembre 2013), Art. 1, pp. 363-385.

[http://www.politicacriminal.cl/Vol_08/n_16/Vol8N16A1.pdf]

OLÁSOLO, Héctor, The criminal responsibility of senior political and military leaders as principals to international crimes, Oxford: Hart Publishers, 2009.

PLUTARCO, Vidas Paralelas, Trad. A. Ranz R., Madrid: Ed. Iberia, 1959.

POLITOFF L. Sergio, Derecho penal, T. I., $2^{\text {a }}$ Ed., Santiago: Ed. Conosur, 2000, pp. 362372 y $375-380$.

, 'El 'Autor detrás del autor'. De la autoría funcional a la responsabilidad penal de las personas jurídicas", en: POLITOFF L., Sergio; MATUS A., Jean Pierre, Gran criminalidad organizada y tráfico ilícito de estupefacientes, Santiago: Ed. Conosur, 2000, pp. 333-414.

"La conspiración para cometer delitos previstos en la Ley sobre Tráfico Ilícito de Estupefacientes”, en POLITOFF L., Sergio; MATUS A., Jean Pierre (Coords.), El tratamiento penal del tráfico ilícito de estupefacientes. Estudios de dogmática y jurisprudencia, Santiago: Ed. Conosur, 1999, pp. 89-109.

POLITOFF L., Sergio; MATUS A., Jean Pierre (Coords.), El tratamiento penal del tráfico ilícito de estupefacientes. Estudios de dogmática y jurisprudencia, Santiago: Ed. Conosur, 1999. , Gran criminalidad organizada y tráfico ilícito de estupefacientes, Santiago: Ed. Conosur, 2000.

POLITOFF, Sergio; MATUS, Jean Pierre; RAMÍREZ, Ma. Cecilia, Lecciones de Derecho penal chileno. Parte General, $2^{\text {a }}$ Ed., Santiago: Ed. Jurídica de Chile, 2004.

, Lecciones de Derecho penal chileno. Parte Especial, 2a Ed., Santiago: Ed. Jurídica de Chile, 2005.

POLITOFF L., Sergio; ORTIZ Q., Luis (Dirs.); MATUS A., Jean Pierre, Texto y comentario del Código penal chileno, T. I, Santiago: Ed. Jurídica de Chile, 2002.

ROXIN, Claus, Täterschaft und Tatherrschaft, $8^{\text {a }}$ Ed., Berlín: De Gruyter, 2006.

GARCÍA-DÍAZ Y CONLLEDO, Miguel, La autoría en Derecho penal, Barcelona: PPU, 1991.

SAMAHA, Joel, Criminal Law, $4^{\text {a }}$ Ed., New York: West Group, 1993.

SATZGER, Helmuth, Internationales und Europäisches Strafrecht, $4^{\mathrm{a}}$ Ed., Baden-Baden (Alemania): Nomos, 2010.

WINTER E., Jaime, La responsabilidad por el mando en el Derecho penal internacional, Tesis Uch, Santiago, 2009. 